\title{
Rapidly solidified nonequilibrium microstructure and phase transformation of laser-synthesized iron-based alloy coating
}

\author{
Xiaolei $\mathrm{Wu}$ * \\ Laboratory for Nonlinear Mechanics of Continuous Media, Institute of Mechanics, Chinese Academy of Sciences, 15 Zhongguancun Road, \\ Beijing 100080, People's Republic of China
}

Received 22 December 1998; accepted 27 March 1999

\begin{abstract}
The rapidly solidified microstructural and compositional features, the precipitation and transformation of carbides during tempering, and the impact wear resistance of an iron-based alloy coating prepared by laser cladding are investigated. The clad coating alloy, a powder mixture of $\mathrm{Fe}, \mathrm{Cr}, \mathrm{W}, \mathrm{Ni}$, and $\mathrm{C}$ with a weight ratio of 10:5:1:1:1, is processed using a continuous wave $\mathrm{CO}_{2}$ laser. Microstructural studies demonstrate that the coating possesses the hypoeutectic microstructure comprising the primary dendritic $\gamma$-austenite and interdendritic eutectic consisting of $\gamma$-austenite and $\mathbf{M}_{7} \mathrm{C}_{3}$ carbides. $\gamma$-Austenite is a non-equilibrium phase with an extended solid solution of alloying elements. During high temperature tempering at $963 \mathrm{~K}$ for $1 \mathrm{~h}$, the precipitation of $\mathrm{M}_{23} \mathrm{C}_{6}, \mathrm{MC}$ and $\mathrm{M}_{2} \mathrm{C}$ carbides in austenite and in situ carbide transformation of $\mathrm{M}_{7} \mathrm{C}_{3}$ to $\mathrm{M}_{23} \mathrm{C}_{6}$ and $\mathrm{M}_{7} \mathrm{C}_{3}$ to $\mathrm{M}_{6} \mathrm{C}$ respectively are observed. In addition, the microstructure of the laser-clad coating reveals an evident secondary hardening and a superior impact wear resistance. C 1999 Elsevier Science S.A. All rights reserved.
\end{abstract}

Keywords: Laser surface cladding; Microstructure; Carbide; Temper; Wear

\section{Introduction}

Laser cladding provides a unique opportunity for non-equilibrium synthesis of materials which possess novel microstructures due to the inherent rapid solidification and high concentration of key elements on the surface [1-4]. Coatings having such microstructures generally cannot be developed by conventional means since metastable phases or extended solid solutions, which are characteristic of the rapid solidification rates, cannot easily be obtained. In addition, coatings are metallurgically bonded to the substrate and their microstructure can be graded during processing to reduce thermal stress gradients occurring as a result of thermal expansion mismatch between the coating and the substrate.

Tailor-made coating materials, with metastable, crystalline and amorphous microstructures, produced by means of laser surface alloying and laser cladding techniques have been researched. $\mathrm{Fe}-\mathrm{C}-\mathrm{X}(\mathrm{X}=\mathrm{Cr}, \mathrm{Mn}, \mathrm{W}$, $\mathrm{Mo}, \mathrm{Ni}, \mathrm{B}$ etc.) alloys are excellent candidates for hard-

\footnotetext{
* Fax: + 86-10-6256-1284.

E-mail address: xlwu@ecc5.imech.ac.cn (X. Wu)
}

facing materials in applications requiring surfaces exhibiting high wear resistance. Microstructural characterization of laser-alloyed $\mathrm{Fe}-\mathrm{C}-\mathrm{Cr}$ has demonstrated the formation of a fully martensitic phase with dislocated lath type substructures and twinned austenite needles or $\mathrm{M}_{23} \mathrm{C}_{6}$ carbides in a dislocated ferrite matrix, depending on the concentration of $\mathrm{Cr}$ [5]. With a similar $\mathrm{Fe}-$ $\mathrm{Cr}-\mathrm{C}$ ternary system, microstructures possessing metastable crystalline and amorphous phase have also been obtained by laser alloying [6]. Wear testing and characterization of a coating by laser cladding powder mixture composed of $\mathrm{Cr}-\mathrm{Ni}-\mathrm{Mo}$ and $\mathrm{Cr}$ carbides have revealed a superior wear resistance, a good interfacial adherence, and a uniform microstructure, as compared with a plasma-sprayed coating having similar compositions [7]. Singh and Mazumder [8] have shown that the existence of a high degree of grain refinement, the formation of metastable $\mathrm{M}_{6} \mathrm{C}$ and $\mathrm{M}_{7} \mathrm{C}_{3}$ carbide, and an increase in solid solubility of alloying elements markedly improve the wear resistance by laser cladding $\mathrm{Fe}-\mathrm{Cr}-\mathrm{Mn}-\mathrm{C}$ alloys. Komvopoulos and Nagarathnam [9,10] have obtained a hard coating with a good resistance against shear deformation and microcracking by laser cladding of $\mathrm{Fe}-\mathrm{Cr}-\mathrm{W}-\mathrm{C}$ alloys. The laser alloying of $\mathrm{Fe}-\mathrm{Cr}-\mathrm{Ni}-$ 
Mo-C alloys produced martensitic, fully austenitic and austenitic-ferritic microstructures depending on the chemical composition, and coatings, with chemical compositions similar to that of conventional austenitic stainless steels, showed better pitting corrosion resistance than their bulk counterparts produced by conventional techniques, despite their high carbon content [11]. In addition to microstructures and properties of the coating, the influence of processing conditions on the microstructure fineness, distribution of alloying elements, geometrical characteristics, microhardness, and toughness of laser-clad coating, etc. were also investigated $[2,5,9]$.

From the foregoing review of the literature, it is apparent that coating materials with novel microstructures and properties superior to those of traditional materials can be successfully developed to adhere strongly to substrates of ordinary metals and alloys by means of laser surface cladding and alloying techniques. Although microstructural modification by laser cladding of the iron-based alloys with various compositions and process parameters has been demonstrated, rather little attention has been given to the microstructural characteristics and the phase transformations of non-equilibrium and metastable phases, which control the mechanical properties of the coating. The objective of the present investigation is to provide a comprehensive analysis of the crystal structures and microchemistries of phases in homogeneous and hard clad coatings developed in the present study and to track systematically the microstructural evolution occurring during subsequent high temperature tempering. Based on the results obtained, the implications of laser cladding to tribological application, where wear-resistant coatings are of primary significance to component durability, will be also discussed.

\section{Experimental procedure}

The clad coating alloy is a blended powder mixture of $\mathrm{Fe}, \mathrm{Cr}, \mathrm{W}, \mathrm{Ni}$ and $\mathrm{C}$ with a weight ratio of 10:5:1:1:1 and purities of 99.70, 98.70, 99.50, 99.97, and 99.99 (all wt.\%), respectively. The real chemical compositions of the coating are determined to be $4.14 \mathrm{C}, 22.73 \mathrm{Cr}, 4.81 \mathrm{~W}$, 4.64Ni, balanced by $\mathrm{Fe}$ (all wt.\%) using the method of the chemical analysis and face scanning via electron probe microanalysis (EPMA) using wavelength-dispersive X-ray spectroscopy (WDS) as well [12]. Chromium has a dual function, i.e. the predominant carbide former and an important alloying element in the matrix. Tungsten is the secondary hardening carbide former and provides additional strength to the matrix. Significant quantities of nickel are added to stabilize the f.c.c. structure as an intrinsic toughness enhancer during service. The substrate material is a $5 \mathrm{CrMnMo}$ steel with main compositions of $0.52 \mathrm{C}, 1.21 \mathrm{Cr}, 1.18 \mathrm{Mn}, 0.33 \mathrm{Mo}$, balanced by $\mathrm{Fe}$ (all wt.\%). Rectangular specimens, $10 \mathrm{~cm}$ long, $4 \mathrm{~cm}$ wide, and $1.5 \mathrm{~cm}$ thick, are austenized at $1153 \mathrm{~K}$ for $20 \mathrm{~min}$, oil cooled, and then tempered at $833 \mathrm{~K}$ for $60 \mathrm{~min}$.

Laser cladding is carried out with a continuous wave $3 \mathrm{~kW} \mathrm{CO}$ laser equipped with a powder delivery system and an argon gas guidance device. A large amounts of experiments are performed to quantify the effect of the laser clad parameters on the properties of the coating on a macroscopic scale, i.e. the thickness, the powderclad efficiency, the volumetric dilution ratio and the crack formation [13]. Within the range of laser parameters, the best results are at a $16 \mathrm{~mm} \mathrm{~s}^{-1}$ beam scanning speed, $3 \mathrm{~mm}$ beam diameter, $2 \mathrm{~kW}$ laser power, and $0.3 \mathrm{~g} \mathrm{~s}^{-1}$ feed rate, resulting in a mean coating thickness of $0.73 \mathrm{~mm}$, a volumetric dilution ratio of about $6 \%$, and free from crack.

Both the as-solidified and the as-aged microstructures during high temperature aging at $963 \mathrm{~K}$ for $1 \mathrm{~h}$ were analyzed using a Philips EM420 analytical transmission electron microscope (ATEM). All of the thin ATEM slices, $0.2 \mathrm{~mm}$ in thickness, were taken using a slowspeed cut-off saw parallel to the cladding surface and at a distance of $0.4 \mathrm{~mm}$ away from the top surface of the coating. Therefore, the actual depth of the specimen for ATEM observation is at the middle part of the molten pool. Slices are then cut into $3 \mathrm{~mm}$ disks by using an ultrasonic disk cutter. Disks are dimpled on both sides by a dimple grinder and subsequently ion milled at an angle of $10^{\circ}$, to perforation under a voltage of $5.5 \mathrm{kV}$. The chemical compositions of each phase are determined using energy-dispersive X-ray analysis (EDX) and an electron energy loss spectrometer (EELS) in conjunction with the ATEM. The electron beam of the ATEM EDX produces an electron spot of about $10 \mathrm{~nm}$ in diameter. The crystallographic phases are also determined by standard X-ray diffraction techniques.

Vickers hardness measurements were carried out with a diamond indenter using a load of $0.2 \mathrm{kgf}$. The impact wear was determined using an impact wear test machine. A sketch of the testing principle of the tester is shown in Fig. 1. The experimental conditions are 0.2 and $3 \mathrm{~J}$ impact work, 120 cycles $\mathrm{min}^{-1}$ impact frequency, and the room temperature. The specimen shape is diameter $10 \mathrm{~mm} \times 40 \mathrm{~mm}$. Multiple laser tracks are used and the shift between two successive tracks is constant. The optimum shift used to ensure a constant thickness coating is determined to be about $25 \%$ of the beam diameter. A GCr15 steel, with main compositions of $1.48 \mathrm{C}, 1.52 \mathrm{Cr}$, balanced by $\mathrm{Fe}$ (all wt.\%.), is used as the friction counterpart rotated at a speed of $120 \mathrm{rpm}$. The heat-treatment condition is $1153 \mathrm{~K}$ for $1 \mathrm{~h}$ austenizing, oil cooling and $853 \mathrm{~K}$ for $2 \mathrm{~h}$ tempering, and the hardness of the specimen is $\mathrm{HRc} 62$. Solid $\mathrm{Al}_{3} \mathrm{O}_{2}$ particles of average size of 380 mesh are used as abrasives. The 


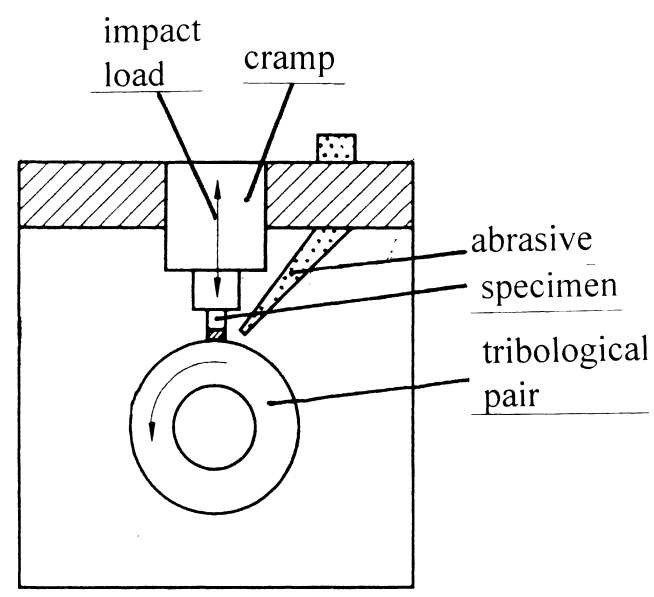

Fig. 1. A sketch of the testing principle of the impact wear tester.

abrasives are fed into the space between the specimen and the counterpart at a flow rate of $180 \mathrm{~g} \mathrm{~min}^{-1}$.

\section{Results and discussion}

\subsection{Laser-clad microstructures}

Fig. 2(a) and (b) presents two ATEM bright-field images showing the microstructures of the laser-clad coating under the laser processing parameters of a
$16 \mathrm{~mm} \mathrm{~s}^{-1}$ beam scanning speed, $3 \mathrm{~mm}$ beam diameter, $2 \mathrm{~kW}$ laser power, and $0.3 \mathrm{~g} \mathrm{~s}^{-1}$ feed rate. Fig. 2(a) reveals the primary solidification phase with the dendritic growth morphology. The corresponding selected area diffraction pattern (SADP) is shown in Fig. 2(c). Analysis of the pattern identifies the primary phase as $\gamma$-austenite of the f.c.c. structure. Fig. 2(b) reveals the interdendritic lamellar eutectic. The corresponding SADP in Fig. 2(d) indicates that the eutectic is composed of $\gamma$-austenite and the $\mathrm{M}_{7} \mathrm{C}_{3}$ carbide. $\mathrm{M}_{7} \mathrm{C}_{3}$ carbides possess a pseudohexagonal close-packed (h.c.p.) crystal structure and the unit cell dimensions are $a_{0}=1.3979 \mathrm{~nm}$ and $c_{0}=0.4618 \mathrm{~nm}$. Thus, the clad coating possesses the hypoeutectic microstructure, i.e. $\gamma+\left(\gamma+\mathrm{M}_{7} \mathrm{C}_{3}\right)$.

It is observed that a high density of dislocations, stacking faults, and twins, exist in both the primary and the eutectic $\gamma$-austenite, as shown in Fig. 3.

The cooling rate is generally inversely proportional to the spacing of the dendrite arm. From the range of spacings between primary dendrites in the clad coating shown in Fig. 2(a) and from results for cooling rates of similar Fe-based alloys [14,15], it may be postulated that the cooling rate is in the range $10^{3}-10^{5} \mathrm{~K} \mathrm{~s}^{-1}$.

Table 1 shows the quantitative microchemistry of the various phases determined by EDX and EELS. It is seen that $\gamma$-austenite is a nonequilibrium phase with

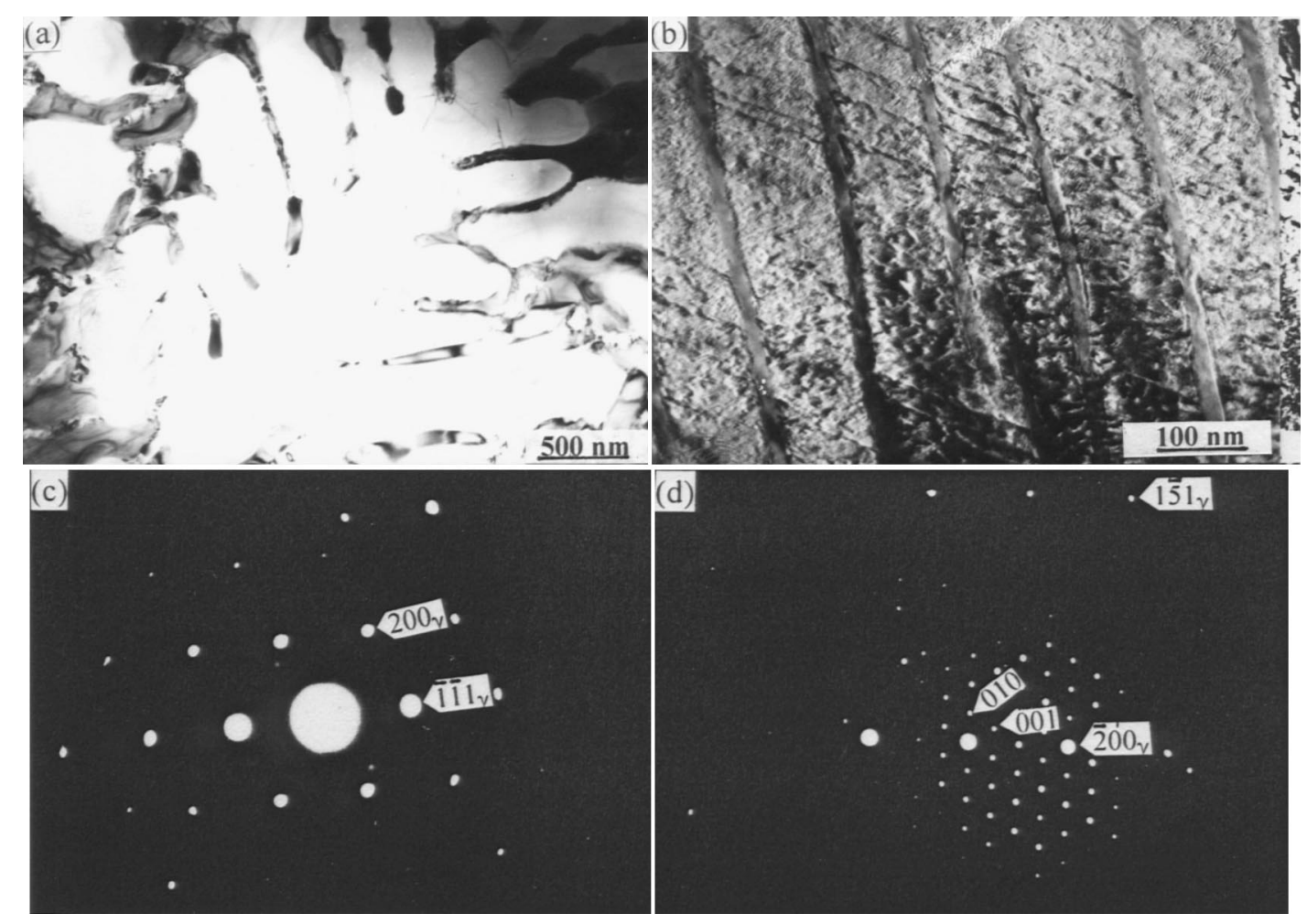

Fig. 2. TEM bright-field images showing the hypoeutectic microstructure of the laser-clad coating: (a) primary dendritic $\gamma$-austenite; (b) interdendritic lamellar eutectic consisting of $\gamma$-austenite and $\mathrm{M}_{7} \mathrm{C}_{3}$ carbide; (c), (d) SADPs of $\gamma$-austenite in (a) and of $\left(\gamma+\mathrm{M}_{7} \mathrm{C}_{3}\right)$ in (b) respectively (laser parameters: $16 \mathrm{~mm} \mathrm{~s}^{-1}$ beam scanning speed, $3 \mathrm{~mm}$ beam diameter, $2 \mathrm{~kW}$ laser power, and $0.3 \mathrm{~g} \mathrm{~s}^{-1}$ feed rate). 


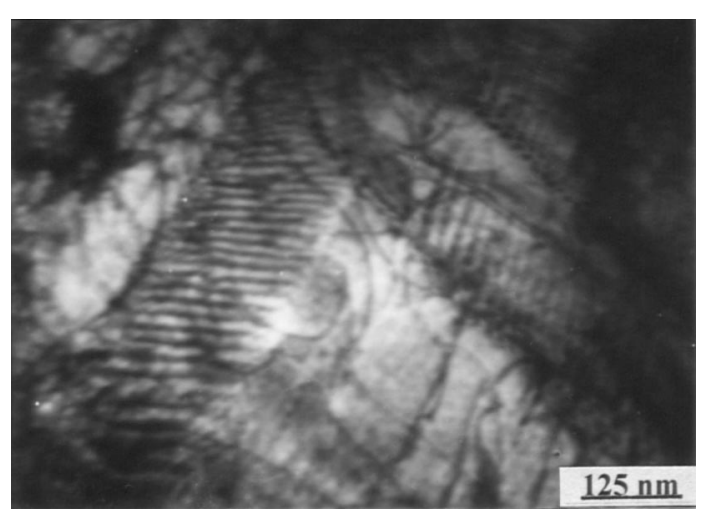

Fig. 3. TEM bright-field image showing high density of dislocations of primary $\gamma$-austenite.

extended alloy element contents. The retention of austenite in the present alloy system at room temperature is in agreement with the findings of other studies dealing with Fe-based alloys $[4,9,10] . \mathrm{M}_{7} \mathrm{C}_{3}(\mathrm{M}=\mathrm{Cr}, \mathrm{Fe}, \mathrm{W}$, and $\mathrm{Ni}$ ) carbide is determined to be a $\mathrm{Cr}$-rich carbides. Also, it is observed that the contents of $\mathrm{Cr}, \mathrm{Ni}$, and $\mathrm{W}$ elements in both austenite and $\mathrm{M}_{7} \mathrm{C}_{3}$ carbides vary with the depth of the molten pool. From the lower to the upper zone of the clad coating, the tungsten content in $\mathrm{M}_{7} \mathrm{C}_{3}$ varies between 1.24 and 15.68 (wt.\%.).

Fig. 4 reveals the X-ray diffraction analysis of the coating. The result indicates that the constituent phases of the laser-clad coating consist of $\gamma$-austenite and the $\mathrm{M}_{7} \mathrm{C}_{3}$ carbide, very consistent with the results of TEM observation. It is determined that the volume fractions of the austenite and the $\mathrm{M}_{7} \mathrm{C}_{3}$ carbide are approximately 59 and $41 \%$ respectively. In addition, no b.c.c. structure, such as $\delta$-ferrite or martensite, exists in the coating according to TEM observation and $\mathrm{X}$-ray diffraction analysis.

Based on the standard X-ray crystallographic procedure [16], the estimated lattice parameter of $\gamma$-austenite is between 0.3684 and $0.3696 \mathrm{~nm}$. Comparison of the experimentally determined $d$ spacings with those given in the standard X-ray powder diffraction data indicates that the lattice parameters of austenite in the coating are significantly greater than those obtained with conventional ingot metallurgical processing techniques. The enhancement of the lattice parameter suggests that significant dissolution of alloying elements,

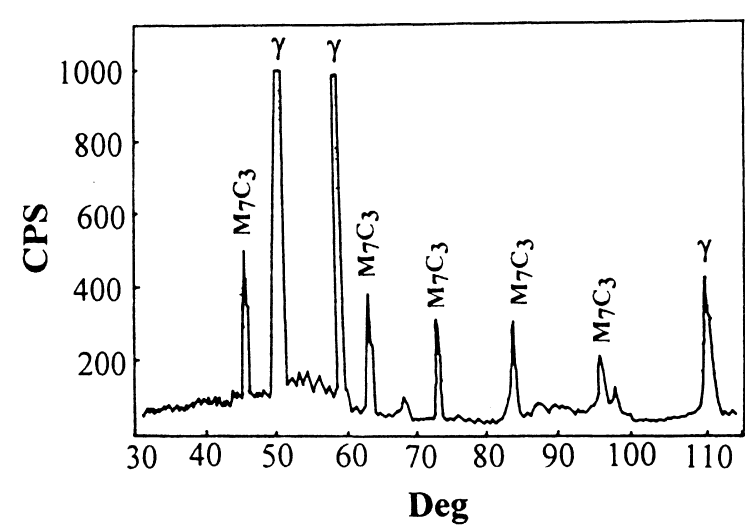

Fig. 4. X-ray diffraction analysis of the as-clad coating (laser parameters: $16 \mathrm{~mm} \mathrm{~s}^{-1}$ beam scanning speed, $3 \mathrm{~mm}$ beam diameter, $2 \mathrm{~kW}$ laser power, and $0.3 \mathrm{~g} \mathrm{~s}^{-1}$ feed rate).

such as $\mathrm{C}, \mathrm{Cr}, \mathrm{Ni}$, and $\mathrm{W}$, commenced in the austenite. Therefore, austenite is a nonequilibrium phase with extended alloy contents. The existence of austenite may be attributed to the low martensite start temperature, the high concentration of austenite stabilizing elements, and the rapid cooling rate.

The average microhardness of the as-clad coating is determined to be about $860 \mathrm{Hv}_{0.2}$. The hardness of both austenite matrix and the carbide phase determines the overall hardness of the coating. The hardness of the $\mathrm{M}_{7} \mathrm{C}_{3}$ carbide is about $1400 \mathrm{kgf} \mathrm{mm}^{-2}$ [17]. Austenite is strengthened by solid solution hardening due to $\mathrm{W}$, $\mathrm{Cr}$, and $\mathrm{Ni}$, by Orowan looping around impenetrable carbides, and dislocation-dislocation interactions.

Recent work $[18,19]$ reveals that in the same alloy system, the primary solidification phase may be $\mathrm{M}_{7} \mathrm{C}_{3}$ carbide when the beam scanning rate is less than $10 \mathrm{~mm} \mathrm{~s}^{-1}$, with the other laser processing parameters unchanged. It is experimentally found that, in the present investigation, an increase in the scanning rate causes a transition of the leading solidification phase from the $\mathrm{M}_{7} \mathrm{C}_{3}$ carbide to austenite. That is to say, there exits phase selection during laser rapid solidification. The influence of solidification conditions on the primary solidification modes in martensitic tool steels and austenitic stainless steels respectively was analyzed [20,21], with the aim of establishing a basis for the selection of the laser treatment parameters that lead to the most

Table 1

ATEM/EDX microchemistry data of phases

\begin{tabular}{lllllll}
\hline Phase structure & \multicolumn{2}{l}{ Element contents (wt.\%) } & & \multirow{2}{*}{ Stoichiometry } \\
\cline { 2 - 6 } & $\mathrm{Cr}$ & $\mathrm{Fe}$ & $\mathrm{W}$ & $\mathrm{Ni}$ & $\mathrm{C}$ & \\
\hline primary $\gamma$ & 11.54 & 82.56 & 1.48 & 3.73 & 1.29 & \\
eutectic $\gamma$ & 16.21 & 67.98 & 4.64 & 5.46 & 2.71 & $\mathrm{Cr}_{4.02} \mathrm{Fe}_{2.48} \mathrm{~W}_{0.32} \mathrm{Ni}_{0.23} \mathrm{C}_{3}$ \\
$\mathrm{M}_{7} \mathrm{C}_{3}$ & 45.84 & 30.46 & 12.91 & 2.98 & 7.89 & \\
\hline
\end{tabular}


favorable microstructures. By using the KGT solidification model [22], the theoretical calculation for competition between ferrite and austenite during solidification is in agreement with experimental observations and it is shown that, although the equilibrium solidification mode is ferrite, the precipitation of primary austenite from the liquid is kinetically favored [21].

\subsection{Carbide precipitation and evolution}

It is considered that the type, size, shape, and distribution of the carbides strongly affect the mechanical properties of the laser-clad coating. The plate-shaped $\mathrm{M}_{7} \mathrm{C}_{3}$ carbide is considered to lower strength and toughness especially at an elevated temperature. The $\mathrm{M}_{7} \mathrm{C}_{3}$ carbide is a metastable phase and its decomposition temperature is about $873 \mathrm{~K}$ [17]. Therefore, the dissolution and transformation of the $\mathrm{M}_{7} \mathrm{C}_{3}$ carbide may occur during high temperature aging. It is expected that a more favorable carbide distribution can be obtained by $\mathrm{M}_{7} \mathrm{C}_{3}$ decomposition. This occurs because $\mathrm{M}_{7} \mathrm{C}_{3}$ carbides can be easily decomposed in a short time at high temperatures. However, the decomposition behavior of $\mathrm{M}_{7} \mathrm{C}_{3}$ carbides formed during the rapid solidification process has not been investigated in detail. Additionally, austenite is also a nonequilibrium phase and as a result, the precipitation reaction of various carbides is thermodynamically favorable.

Fig. 5(a) is a TEM bright-field image revealing an in situ transformation of eutectic $\mathrm{M}_{7} \mathrm{C}_{3}$ to $\mathrm{M}_{23} \mathrm{C}_{6}$ carbides. $\mathrm{M}_{7} \mathrm{C}_{3}$ carbide possesses a light black contrast. It is observed that the fine spherical $\mathrm{M}_{23} \mathrm{C}_{6}$ carbide, with a dark black contrast, nucleates either within $\mathrm{M}_{7} \mathrm{C}_{3}$ carbides or at the interface between $\mathrm{M}_{7} \mathrm{C}_{3}$ carbide and austenite matrix, as indicated by arrows. Also, $\mathrm{M}_{23} \mathrm{C}_{6}$ carbides may also form directly in austenite matrix. In the case of tempering for a long time, $\mathrm{M}_{23} \mathrm{C}_{6}$ carbides grow from the outside inward and then $\mathrm{M}_{7} \mathrm{C}_{3}$ carbides disappear. The decomposition of $\mathrm{M}_{7} \mathrm{C}_{3}$ carbides can be expressed as $\mathrm{M}_{7} \mathrm{C}_{3} \rightarrow \mathrm{M}_{23} \mathrm{C}_{6}$. Fig. 5(b) is an SADP taken from $\mathrm{M}_{23} \mathrm{C}_{6}$ carbides and the surrounding austenite matrix. It is determined by EDX that the $\mathrm{M}_{23} \mathrm{C}_{6}$ carbide belongs to a $\mathrm{Cr}-\mathrm{Fe}$-rich carbide. Its stoichiometry is $\mathrm{Cr}_{11.94} \mathrm{Fe}_{10.76} \mathrm{~W}_{0.12} \mathrm{Ni}_{0.18} \mathrm{C}_{6}$.

Fig. 6(a) and (b) are TEM bright-field images revealing an in situ transformation of $\mathrm{M}_{7} \mathrm{C}_{3}$ to $\mathrm{M}_{6} \mathrm{C}$ carbides. The lamellar and large granular carbides are $\mathrm{M}_{7} \mathrm{C}_{3}$ carbides with a light black contrast. Fine granular carbides with a dark black contrast are determined to be $\mathrm{M}_{6} \mathrm{C}$-type carbides. Fig. 6(c) and (d) show SADPs of $\mathrm{M}_{7} \mathrm{C}_{3}$ and $\mathrm{M}_{6} \mathrm{C}$ respectively taken from Fig. 6(a). It can be seen that $\mathrm{M}_{6} \mathrm{C}$ carbides nucleate at the $\mathrm{M}_{7} \mathrm{C}_{3}$-austenite interface, as indicated by arrows. Thus, the formation of $\mathrm{M}_{6} \mathrm{C}$ carbides may be described as $\mathrm{M}_{7} \mathrm{C}_{3}+\gamma \rightarrow \mathrm{M}_{6} \mathrm{C}$. This kind of in situ transformation requires the partition of tungsten. The supply of tungsten to form $\mathrm{M}_{6} \mathrm{C}$ carbides is provided by the interface diffusion rather than volume diffusion in $\mathrm{M}_{7} \mathrm{C}_{3}$ carbides. This reaction, although starting at the interface, is sometimes also called in situ [23,24]. As this reaction proceeds, most $\mathrm{M}_{7} \mathrm{C}_{3}$ carbides will eventually be replaced by $\mathrm{M}_{6} \mathrm{C}$ carbides. According to the results of the EDX analysis of the tungsten content, the stoichiometry of $\mathrm{M}_{6} \mathrm{C}$ carbides varies between $\mathrm{W}_{3.7} \mathrm{Cr}_{1.2} \mathrm{Fe}_{1.1} \mathrm{C}$ and $\mathrm{W}_{3.2} \mathrm{Cr}_{1.4} \mathrm{Fe}_{1.4} \mathrm{C}$.

The distinction between $\mathrm{M}_{6} \mathrm{C}$ and $\mathrm{M}_{23} \mathrm{C}_{6}$ carbides is difficult because both structures are based on the same f.c.c. Bravais lattice with very close sizes of the unit cell, i.e. 1.113 and $1.086 \mathrm{~nm}$, respectively. However, $\mathrm{M}_{6} \mathrm{C}$ and $\mathrm{M}_{23} \mathrm{C}_{6}$ belong to $F d 3 m$ and $F m 3 m$ space groups respectively [25]. Also, $\mathrm{M}_{6} \mathrm{C}$ and $\mathrm{M}_{23} \mathrm{C}_{6}$ are $\mathrm{W}$-rich and $\mathrm{Cr}-\mathrm{Fe}$-rich carbides, respectively. Thus, it is possible to

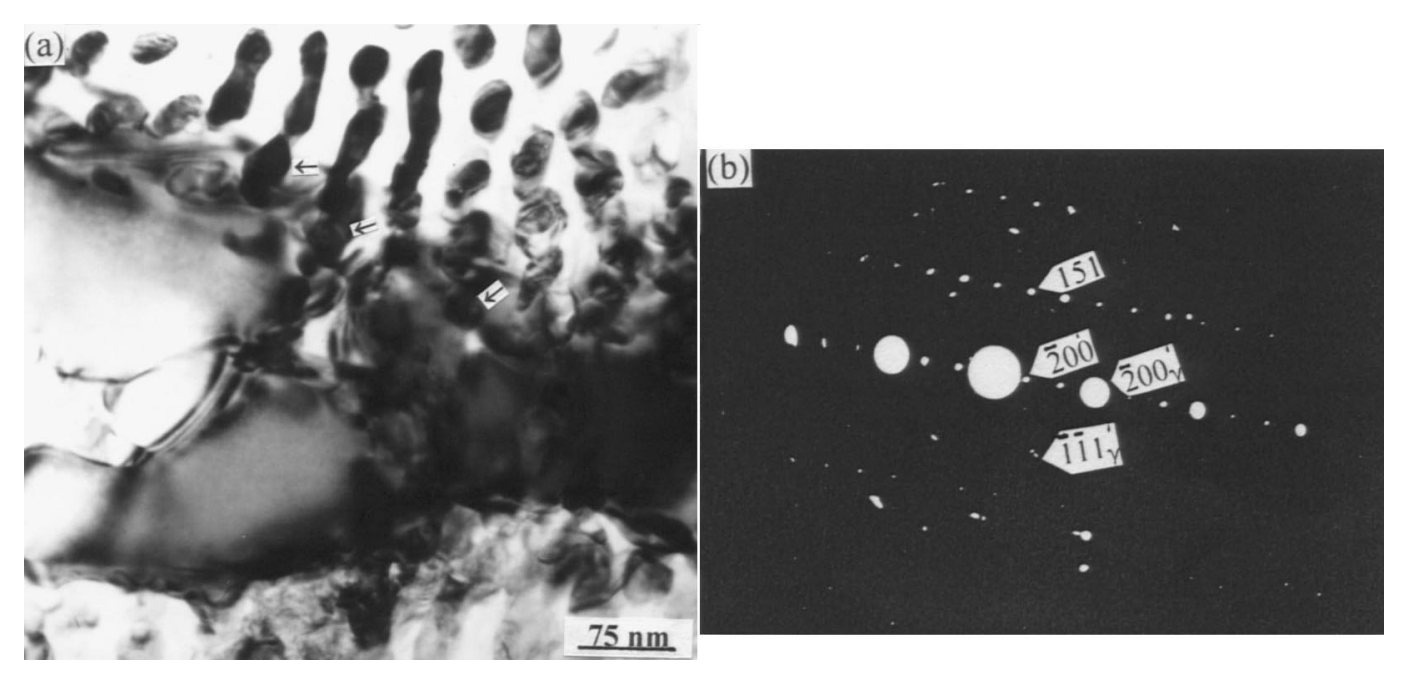

Fig. 5. (a) TEM bright-field image showing the in situ transformation of $M_{7} C_{3}$ to $M_{23} C_{6}$ carbide and (b) SADP of $\left(\gamma+M_{23} C_{6}\right.$ carbide). 


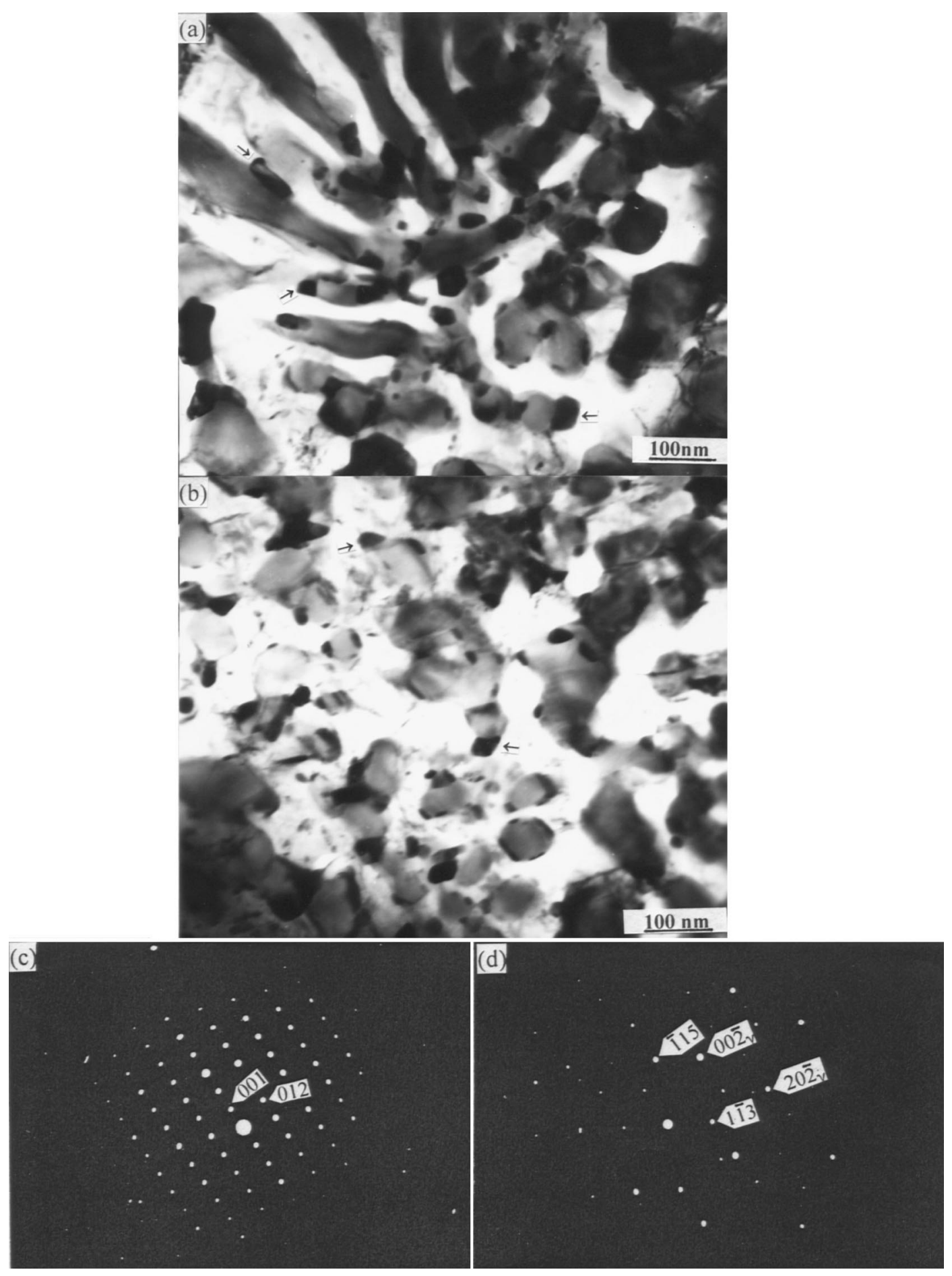

Fig. 6. (a), (b) TEM bright-field images showing the in situ transformation of $M_{7} C_{3}$ to $M_{6} C$ carbide, and (c), (d) SADPs of (c) $M_{7} C_{3}$ and of (d) $\gamma+\mathrm{M}_{6} \mathrm{C}$ carbide in (a). Fine granular $\mathrm{M}_{6} \mathrm{C}$ carbides formed in situ, with a deep black contrast, are indicated by arrows.

discriminate one from the other by using the extinction rules for the different space groups and by analysis of element compositions.

Fig. 7(a) and (b)shows TEM bright-field images illustrating plate-like $\mathrm{M}_{23} \mathrm{C}_{6}$ carbides precipitated around dislocations in the primary and eutectic austenite respectively. Fig. 7(c) and (d) shows their SADPs respectively. $\mathrm{M}_{23} \mathrm{C}_{6}$ carbides are determined also to be $\mathrm{Cr}-\mathrm{Fe}$-rich carbides by using EDX.

Fig. 8 shows TEM bright-field images revealing small fibrous and needle-like carbides in the eutectic austenite. These carbides are determined to be $\mathrm{W}_{2} \mathrm{C}$ and $\mathrm{WC}$ 

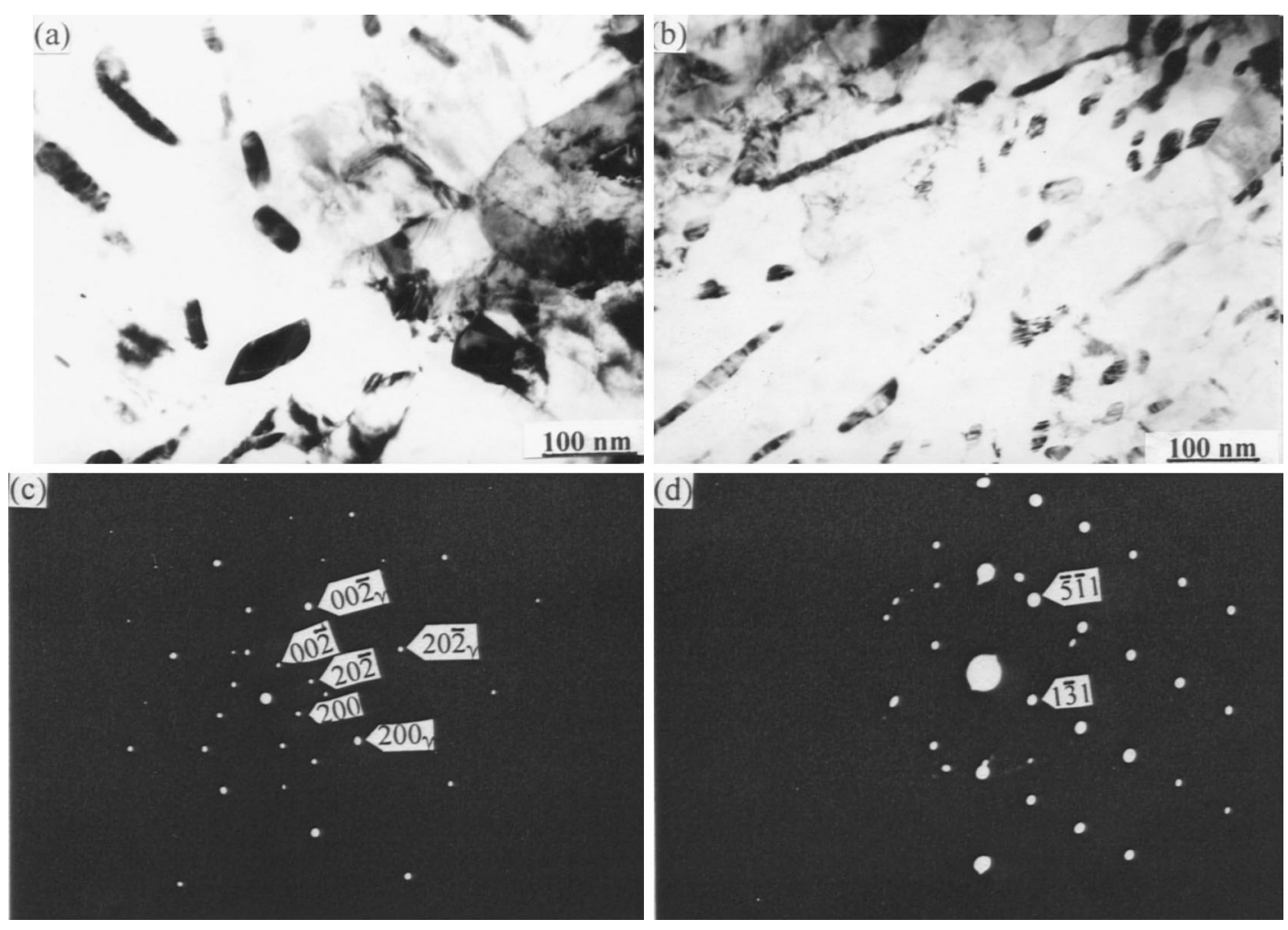

Fig. 7. TEM bright-field images showing the plate-like $\mathrm{M}_{23} \mathrm{C}_{6}$ carbide precipitated in (a) the primary and (b) the eutectic austenite, and (c), (d) their respective SADPs.

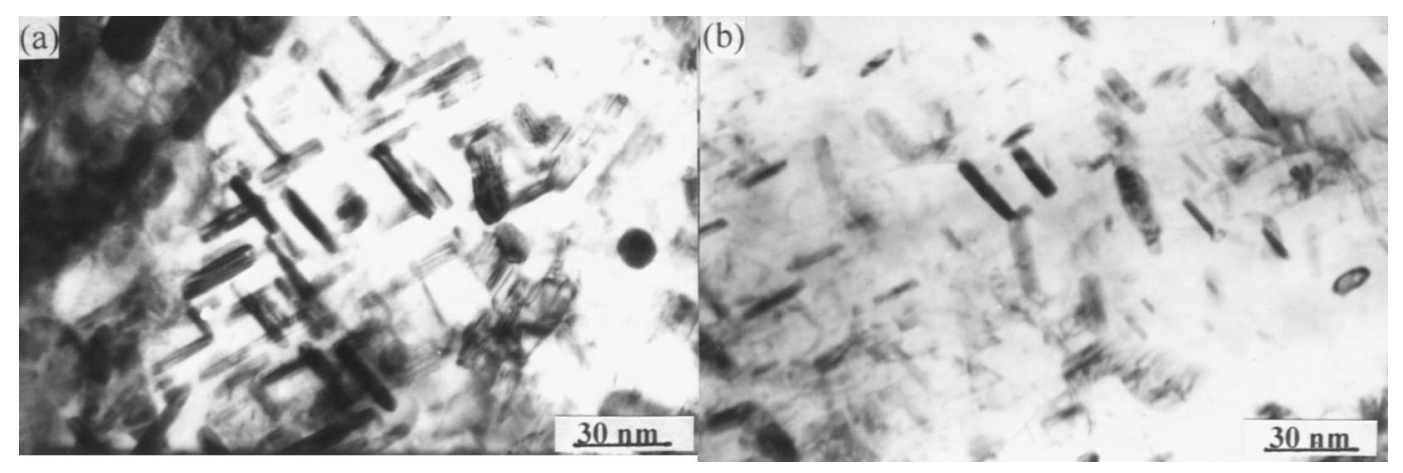

Fig. 8. TEM bright-field images showing (a) $\mathrm{M}_{2} \mathrm{C}$ and (b) $\mathrm{MC}$ precipitated in eutectic austenite.

carbides, respectively, by diffraction analyses. It is noted that the $\mathrm{W}_{2} \mathrm{C}$ and $\mathrm{WC}$ carbides mainly nucleated at dense dislocations, and their sizes are in a range from 10 to $30 \mathrm{~nm}$. In the peak-aged temperature of $690^{\circ} \mathrm{C}$, the fine $\mathrm{W}_{2} \mathrm{C}$ and $\mathrm{WC}$ carbides are densely dispersed and thus lead to a strong secondary hardening. The secondary hardening carbides often nucleate at the original carbide-matrix interface, dislocations, twin and lath boundaries and original austenite grain boundaries (GBs). Carbides which form at the original carbide/matrix interface and austenite GBs do not contribute significantly to strength, because nucleation sites are too scattered, but those which nucleate at dislocations and twin and lath boundaries can make a large contribution to strength.

Since the carbide precipitation is accompanied by a decrease in supersaturation of alloy elements, austenite will be destabilized and partially transform to martensite $(\alpha)$ during cooling, leading to a further increase in the overall hardness of the layer. The martensite formed in the primary austenite is illustrated in Fig. 9.

Fig. 10 shows the X-ray diffraction analysis of the as-aged microstructure, very consistent with the above TEM observation. Quantitative X-ray diffraction phase 


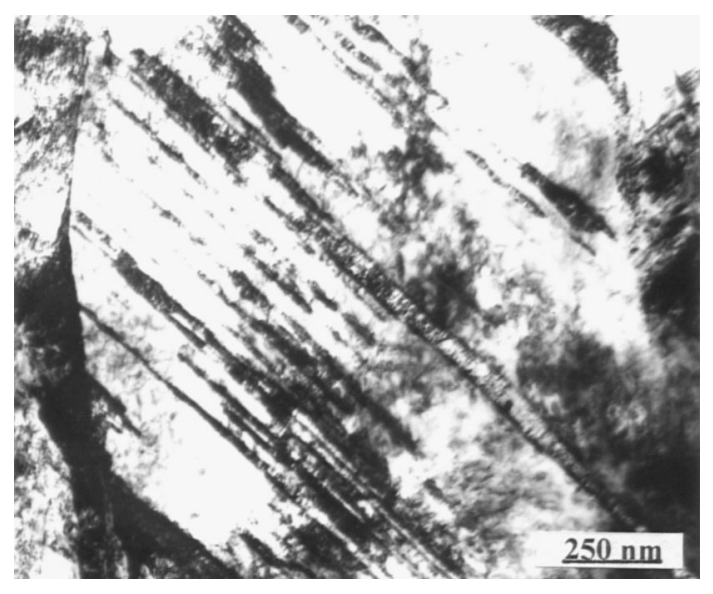

Fig. 9. TEM bright-field image showing the formation of martensite in the primary austenite during tempering.

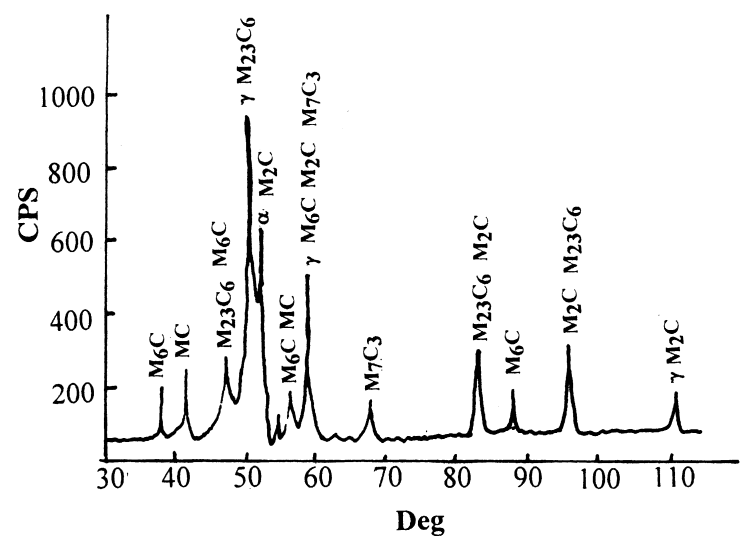

Fig. 10. X-ray diffraction analysis of the peak-aged microstructure of the coating.

analysis reveals that the volume fraction of austenite is about $21 \%$ in the peak-aged microstructure of the coating [19].

Based upon the investigated results, the solidification and evolution sequence of phases can be represented as follows:

$$
\begin{gathered}
\mathrm{L} \rightarrow \gamma+\mathrm{L} \rightarrow \gamma+\left(\gamma+\mathrm{M}_{7} \mathrm{C}_{3}\right) \rightarrow\left(\gamma+\mathrm{M}_{23} \mathrm{C}_{6}+\alpha\right) \\
+\left(\gamma+\mathrm{M}_{23} \mathrm{C}_{6}+\mathrm{M}_{2} \mathrm{C}+\mathrm{MC}+\mathrm{M}_{6} \mathrm{C}\right)
\end{gathered}
$$

\subsection{Secondary hardening}

Fig. 11 shows the microhardness variation of the laser-clad coating with the tempering temperature. It is seen that the microstructure of the coating possesses an evident secondary hardening which is attributed to the precipitation of $\mathrm{M}_{2} \mathrm{C}$ and $\mathrm{MC}$ carbides. The peak temperature and peak microhardness are experimentally determined to be $670^{\circ} \mathrm{C}$ and $1140 \mathrm{Hv}_{0.2}$, respectively.

The presence of a large amount of austenite has a strong influence on the aging behavior. The austenite

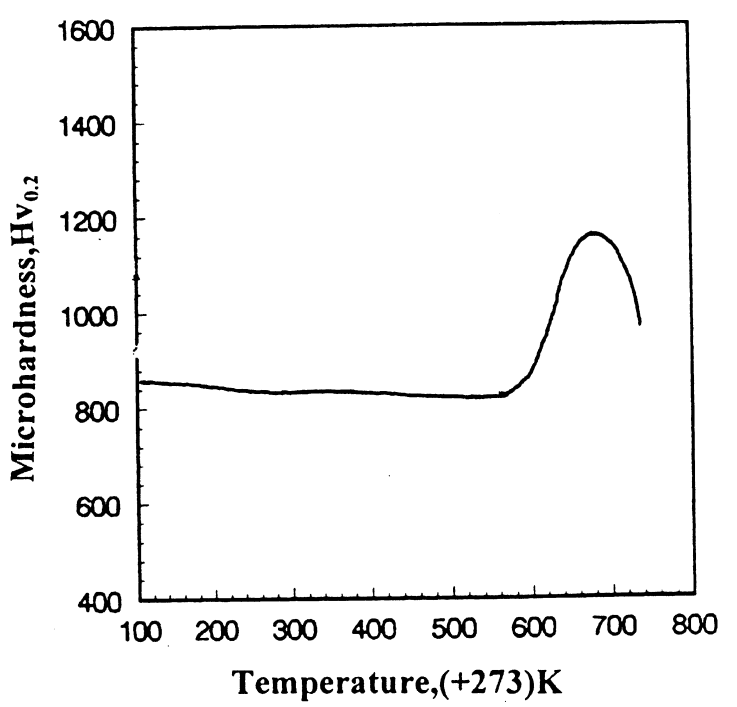

Fig. 11. Secondary hardening of the coating.

presents a higher solute content. As a result, austenite is very stable and only transform at temperatures where precipitation of alloy carbides occurs. In conventionally hardened steels, the most likely nucleation sites for carbides are the original austenite grain boundaries, and precipitation from austenite will not contribute significantly to hardness, but in the present coating austenite contains a high density of dislocations. Since the precipitation of the $\mathrm{M}_{2} \mathrm{C}$ and $\mathrm{MC}$ carbides occurs by nucleation and growth on dislocations and other crystallographic defects, the precipitation are finely dispersed and as a result, they will contribute significantly to strengthening the austenite and to retarding its recovery. Therefore, the high secondary hardening temperature and peak hardness are mainly attributed to a delay in the onset of disperse $\mathrm{M}_{2} \mathrm{C}$ and $\mathrm{MC}$ precipitation. Additionally, diffusion coefficients of the alloy elements in austenite are several orders of magnitude lower than those for ferrite or martensite [26]. As a result, secondary hardening will be delayed until higher temperatures.

\subsection{Wear resistance}

Fig. 12 shows the preliminary impact wear data for the as-clad and peak-aged microstructures, respectively, as a function of impact work of 0.2 and $3 \mathrm{~J}$, respectively. For comparison, two additional values are also presented: data for conventional hardened and laserremelted AISI M4 high speed steel (HSS), respectively. For all data presented, each data point represents the average of at least three separate tests. The composition of the HSS is $1.33 \mathrm{C}, 4.3 \mathrm{Cr}, 9.3 \mathrm{~W}, 4.9 \mathrm{Mo}, 4.2 \mathrm{~V}$, balanced by $\mathrm{Fe}$ (all wt.\%.). For wear specimens of HSS, the conventionally hardened is quenching at $1250^{\circ} \mathrm{C}$ for $30 \mathrm{~min}$, and triple tempered at $560^{\circ} \mathrm{C}$ for $2 \mathrm{~h}$. Laserremelted parameters were $2 \mathrm{~kW}$ laser power, $3 \mathrm{~mm}$ beam 


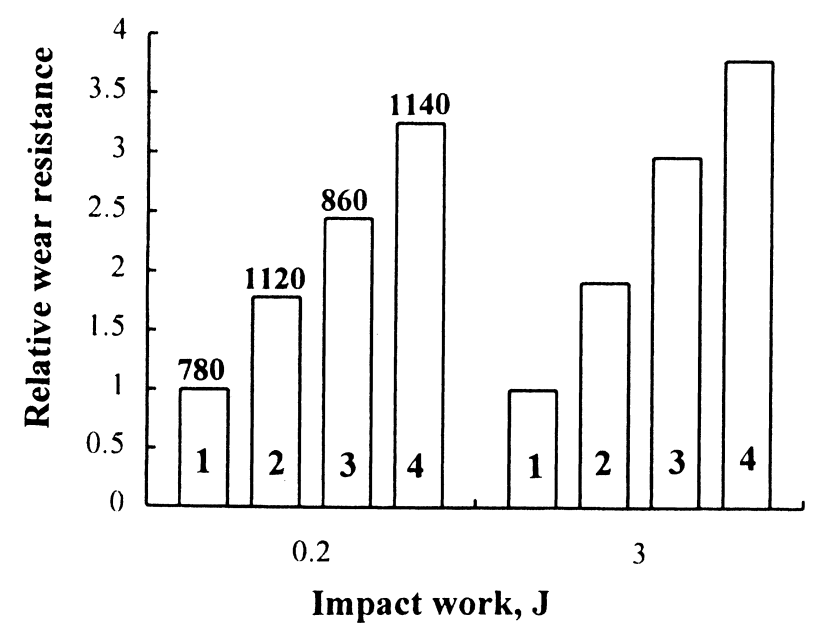

Fig. 12. Relative wear resistance of the clad coating (microhardness indicated above bars): 1, conventionally hardened HSS; 2, laserremelted HSS; 3, as-clad coating; 4, as-aged coating.

diameter and $20 \mathrm{~mm} \mathrm{~s}^{-1}$ scanning speed. Laser-remelted samples were then heat treated at $600^{\circ} \mathrm{C}$ for $2 \mathrm{~h}$. The relative wear resistance was obtained by calculating the ratios of the measured weight change of conventionally treated HSS to that of laser-treated coatings.

It can be seen that the relative wear resistance of the peak-aged clad coating is the highest. The observation using scanning electron microscopy indicates that the wear mechanism changes from microcutting to microcracking with increasing impact work from $0.2 \mathrm{~J}$ to $3 \mathrm{~J}$ [12].

Basically, to improve effectively the fatigue and impact wear, one should reduce surface and subsurface plastic deformation, crack initiation, and crack growth. The onset of microcracking depends on the fracture toughness of the materials. The wear resistance will enhance with an increase in fracture toughness when microcracking becomes the predominant wear mechanism [27]. The present microstructures of the laser-clad coating can be considered as a composite material consisting of a ductile matrix and dispersely distributed hard carbide phases. Carbides contribute very substantially to the hardness of the clad coating. Austenite prevents carbides from breaking loose during wear. Furthermore, austenite also adjusts for both internal stresses after laser cladding to prevent cracking and external stresses during wear. Thus, austenite provides the coating ductility necessary to adjust for stresses imposed on the coating. Additionally, materials which have finely grained microstructures and exhibit high hardness and toughness are prime candidates for improving the impact wear resistance. Komvopoulos et al. [9] showed that the fine-grained austenite matrix with $\mathrm{M}_{7} \mathrm{C}_{3}$ carbide precipitates obtained for laser-clad $\mathrm{Fe}-\mathrm{Cr}-\mathrm{W}-\mathrm{C}$ alloy attributes to a higher resistance against plastic shear deformation and good toughness.
Therefore, it can be concluded that the superior impact wear resistance may be attributed to the presence of a certain amount of ductile austenite in both as-clad and peak-aged laser-clad coatings.

\section{Summary}

(1) The hypoeutectic microstructure, i.e. $\gamma+\left(\gamma+\mathrm{M}_{7} \mathrm{C}_{3}\right)$, is obtained by laser cladding $\mathrm{Fe}-\mathrm{Cr}-\mathrm{W}-$ $\mathrm{Ni}-\mathrm{C}$ alloys under the process conditions reported here. The $\gamma$-austenite is a non-equilibrium phase with extended solid solution and a high density of dislocations.

(2) During high temperature tempering, the in situ transformations of $\mathrm{M}_{7} \mathrm{C}_{3}$ to $\mathrm{M}_{23} \mathrm{C}_{6}$ and $\mathrm{M}_{7} \mathrm{C}_{3}$ to $\mathrm{M}_{6} \mathrm{C}$ and precipitation of $\mathrm{M}_{23} \mathrm{C}_{6}, \mathrm{MC}$ and $\mathrm{M}_{2} \mathrm{C}$ carbides in austenite are observed.

(3) The clad microstructure possesses secondary hardening characteristics. The peak hardening temperature and peak hardness are $690^{\circ} \mathrm{C}$ and $1140 \mathrm{Hv}_{0.2}$, respectively. The clad coating also reveals the better impact wear resistance.

\section{Acknowledgements}

This work is supported by the National Natural Science Foundation of China under No. 59836220, the Major Science Research Foundation of Chinese Academy of Science under No. KY951-A1-601-03, and Postdoctoral Research Foundation of China under No.4868. These supports are gratefully acknowledged.

\section{References}

[1] W.M. Steen, Met. Mater. 1 (1985) 730-736.

[2] W.M. Steen, Laser Material Processing, Springer, Berlin, 1991, pp. 172-219.

[3] C.W. Draper, J.M. Poate, Int. Met. Rev. 30 (1985) 85-108.

[4] J. Mazumder, in: J. Mazumder, O. Conde, R. Villar, W. Steen (Eds.), NATO ASI Series E: Applied Sciences Vol. 307, Kluwer Academic Publishers, Dordrecht, The Netherlands, 1996, pp. $47-75$.

[5] P.A. Molian, W.E. Wood, Mater. Sci. Eng. 56 (1982) 271-277.

[6] S. Das, I. Dumler, J. Mazumder, in: M.F. Kimmitt (Ed.), Proceedings 2nd International Conference on Lasers in Manufacturing, Birmingham, United Kingdom, March 26-28, 1985, IFS Publications, Bedford, UK, 1985, pp. 73-84.

[7] A. Belmondo, M. Castagna, Thin Solid Films 64 (1979) 249-256.

[8] J. Singh, J. Mazumder, Metall. Trans. A 18 (1987) 313-322.

[9] K. Komvopoulos, K. Nagarathnam, J. Eng. Mater. Technol., Trans. ASME 112 (1990) 131-143.

[10] K. Nagarathnam, K. Komvopoulos, Metall. Trans. A 24 (1993) $1621-1629$.

[11] M.A. Anjos, R. Vilar, R. Li, M.G. Ferreira, W.M. Steen, K. Watkins, Surf. Coat. Technol. 70 (1995) 235-242.

[12] X.L. Wu, Postdoctor Working Report, Institute of Mechanics, Chinese Academy of Sciences, Beijing, 1998, pp. 4-11. 
[13] X.L. Wu, G.X. Luo, G.N. Chen, Proceedings 6th International Conference of IFHT (International Federation for Heat Treatment and Surface Engineering), Kyongju, South Korea (1997) 190-197.

[14] T.R. Anantharaman, C. Suryanarayana, in: G.S. Ansell, D.J. Fisher, P. Haasen, J. Weertman, F.H. Wohlbier (Eds.), Rapidly Solidified Metals: A Technological Overview Key Engineering Materials Vol. 17, Trans Tech, Aedermannsdort, Switzerland, 1987, pp. 159-186.

[15] J.F. Flinn, Rapid Solidification Technology for Reduced Consumption of Strategic Materials, Noyes, Park Ridge, NJ, 1985, pp. $42-64$.

[16] B.D. Cullity, Elements of X-Ray Diffraction, Addison-Wesley, Reading, MA, 1978, pp. 324-371.

[17] J.P. Morniroli, E. Bauer-Grosse, M. Gantois, Philos. Mag. A 48 (1983) 311-319.

[18] X.L. Wu, G.N. Chen, Acta Metall. Sinica 17 (1998) 1033-1038.
[19] X.L. Wu, G.N. Chen, in: Z.L. Chen, Z.J. Shao (Eds.), Proceedings Asian Conference on Heat Treatment of Materials, Machine Press, Beijing, China, 1998, pp. 425-426.

[20] R. Colaco, R. Vilar, Surf. Eng. 12 (1996) 319-325.

[21] R. Colaco, R. Vilar, Scr. Mater. 36 (1997) 199-205.

[22] W. Kurz, B. Giovanola, R. Trivedi, Acta Metall. 34 (1986) $823-830$.

[23] A.T. Davenport, R.W.K. Honeycombe, Met. Sci. 9 (1975) 201-209.

[24] D.V. Shtansky, G. Inden, Acta Mater. 45 (1997) 2861-2878.

[25] T.F. Liu, S.W. Peng, Y.L. Lin, C.C. Wu, Metall.Trans. A 21 (1990) 567-574.

[26] R. Vilar, R. Colaco, A. Almeida, in: J. Mazumder, O. Conde, R. Villar, W. Steen (Eds.), NATO ASI Series E: Applied Sciences Vol. 307, Kluwer Academic Publishers, Dordrecht, The Netherlands, 1996, pp. 453-478.

[27] K.H. Zum Gahr, Microstructure and Wear of Materials, Elsevier, Amsterdam, 1987, pp. 71-93. 